\title{
Effects of Velocity and Thermal Slip Conditions with Radiation on Heat Transfer Flow of Ferrofluids
}

\author{
Maisha Islam Sejunti1, Tania S. Khaleque ${ }^{2 *}$ \\ ${ }^{1}$ Department of Basic Science \& Humanities, University of Asia Pacific, Dhaka, Bangladesh \\ ${ }^{2}$ Department of Applied Mathematics, University of Dhaka, Dhaka, Bangladesh \\ Email: mislam@uap-bd.edu, tania.khaleque@du.ac.bd
}

How to cite this paper: Sejunti, M.I. and Khaleque, T.S. (2019) Effects of Velocity and Thermal Slip Conditions with Radiation on Heat Transfer Flow of Ferrofluids. Journal of Applied Mathematics and Physics, 7, 1369-1387.

https://doi.org/10.4236/jamp.2019.76092

Received: April 25, 2019

Accepted: June 27, 2019

Published: June 30, 2019

Copyright () 2019 by author(s) and Scientific Research Publishing Inc. This work is licensed under the Creative Commons Attribution International License (CC BY 4.0).

http://creativecommons.org/licenses/by/4.0/

\begin{abstract}
To analyze the thermal convection of ferrofluid along a flat plate is the persistence of this study. The two-dimensional laminar, steady, incompressible flow past a flat plate subject to convective surface boundary condition, slip velocity in the presence of radiation has been studied where the magnetic field is applied in the transverse direction to the plate. Two different kinds of magnetic nanoparticles, magnetite $\mathrm{Fe}_{3} \mathrm{O}_{4}$ and cobalt ferrite $\mathrm{CoFe}_{2} \mathrm{O}_{4}$ are amalgamated within the base fluids water and kerosene. The effects of various physical aspects such as magnetic field, volume fraction, radiation and slip conditions on the flow and heat transfer characteristics are presented graphically and discussed. The effect of various dimensionless parameters on the skin friction coefficient and heat transfer rate are also tabulated. To investigate this particular problem, numerical computations are done using the implicit finite difference method based Keller-Box Method.
\end{abstract}

\section{Keywords}

Ferrofluids, Keller-Box Method, Velocity Slip, Thermal Slip, Heat Transfer

\section{Introduction}

Owing to low thermal conductivity of the customary heat transfer fluids such as water, oil and ethylene glycol, the act of engineering apparatus such as heat exchangers and electronic devices face complications. To recover this problem, fluids with higher thermal conductivity like nanofluids are used as additional to these fluids [1]. A nanofluid is a class of fluids comprising nanoparticles with the size range under $100 \mathrm{~nm}$ that are uniformly and stably adjourned in a liquid. The 
nanoparticles used in nanofluids are made of metals, oxides, carbides, or carbon nanotubes. Communal base fluids include water, ethylene glycol and oil [2].

Among various kinds of explores on nanofluids, some of the studies have been absorbed on the nanofluids prepared by diffusing magnetic nanoparticles in a transporter liquid. These are called "ferrofluids". This is a liquid that becomes highly magnetized in the presence of a magnetic field. Ferrofluids are colloidal liquids made of nanoscale particles (diameter usually 10 nanometers or less) of magnetite, hematite or some other ferromagnetic (metallic) such as iron $(\mathrm{Fe})$, cobalt (Co), and nickel (Ni) as well as their oxides such as magnetite $\left(\mathrm{Fe}_{3} \mathrm{O}_{4}\right)$ and ferrites (MnZn, Co ferrites) particles suspended in a carrier fluid (usually an organic solvent or water) [3] [4] [5]. A crunching process for ferrofluid was designed in 1963 by NASA's Steve Papell as a liquid rocket fuel that could be drawn toward a pump inlet in a weightless environment by applying a magnetic field [6]. The name "ferrofluid" was introduced, the process enhanced, more highly magnetic liquids manufactured, supplementary carrier liquids discovered, and the physical chemistry elucidated by R.E. Rosensweig and colleagues [6]; which evolved as a new branch of fluid mechanics termed ferrohydro dynamics. The applications of ferrofluids are enormous in real life sectors like technological applications and materials research. Ferrofluids have vast applications in biomedical sectors such as cancer treatment and Magnetic Resonance Imaging (MRI).

The technology for production for nanoparticles and suspensions, synthesis of nanofluids, thermal transport in stationary fluids, thermal conductivity in nanofluids, convective heat transfer under both natural and forced flow and future developments in nanotechnology have been thoroughly studied by many researchers [7] [8] [9]. Magnetohydrodynamic (MHD) flow and heat transfer from fluids along flat plates have many engineering submissions in different industries. Most of the former studies explore MHD convection heat transfer from surfaces under no slip condition [10] [11] [12] [13] [14]. But in many situations, fluids demonstrate boundary slip for example, micro-scale-fluid dynamics in Micro-Electro-Mechanical System (MEMS). The studies interrelated to slip boundary can be originated by Cao and Baker [15]. Different aspects of the effect of thermal slip condition over a permeable stretching sheet, shrinking sheet and more recently the effects of thermal radiation and ohmic dissipation are also investigated [16] [17] [18]. The MHD boundary layer flow and heat transfer of ferrofluids along a flat plate or an oscillatory infinite sheet with various slip conditions have been studied by different authors [19]-[24]. Ferrofluid properties are derived using the volume fraction of solid nanoparticles in combination with the properties of base fluid and nanoparticles. This model formerly industrialized by Choi [8] has been used among others. The studies related to the use of ferrofluids have been led by to enhance heat transfer in the boundary layer and the convective stability of ferrofluids in magnetic field [16] could be helpful in understanding the physics behind the flow of ferrofluids along plates. However, no attempts so far have been made to analyze heat transfer flow of ferrofluids along a flat plate with velocity and thermal slip conditions with radiation. 


\section{Mathematical Formulation}

\subsection{Governing Equations}

Consider the convective heat transfer of selected ferrofluids along a stationary flat plate in a constant magnetic field. The plate is embedded in a medium saturated with water- or kerosene-based ferrofluids. The flow is assumed to be laminar, steady, incompressible and two-dimensional. The base fluids and the selected nanoparticles are assumed to be in thermal equilibrium. In the presence of magnetic field, the ferroparticles moments almost instantly orient along the magnetic field lines and when the magnetic field is removed, the particles moments are quickly randomized. This orientation along the magnetic-field lines shows a certain precise positioning of the ferroparticles depending upon the position of the magnetic field (Figure 1).

The hydrodynamic slip is assumed at the fluid-solid interface with convective surface boundary condition. Here, we consider a situation where the work done by a fluid on adjacent layers due to action of shear forces that is transformed into heat is negligible compared to radiation. The viscous dissipation is insignificant for low viscous flow such as laminar flow. So, we have neglected the viscous dissipation in this study. The constant temperature $T_{w}$ is assumed to be greater than the ambient temperature $T_{\infty}$. Using an order-of-magnitude analysis, the standard boundary layer equations for this problem can be written as follows:

$$
\begin{gathered}
\frac{\partial u}{\partial x}+\frac{\partial v}{\partial y}=0 \\
u \frac{\partial u}{\partial x}+v \frac{\partial u}{\partial y}=v_{n f} \frac{\partial^{2} u}{\partial y^{2}}-\frac{\sigma B^{2}(x)}{\rho_{n f}}\left(u-U_{\infty}\right) \\
u \frac{\partial T}{\partial x}+v \frac{\partial T}{\partial y}=\alpha_{n f} \frac{\partial^{2} T}{\partial y^{2}}-\left(\frac{1}{\rho C_{p}}\right)_{n f} \frac{\partial q_{r}}{\partial y}
\end{gathered}
$$

The transverse magnetic field is assumed to be a function of the distance from

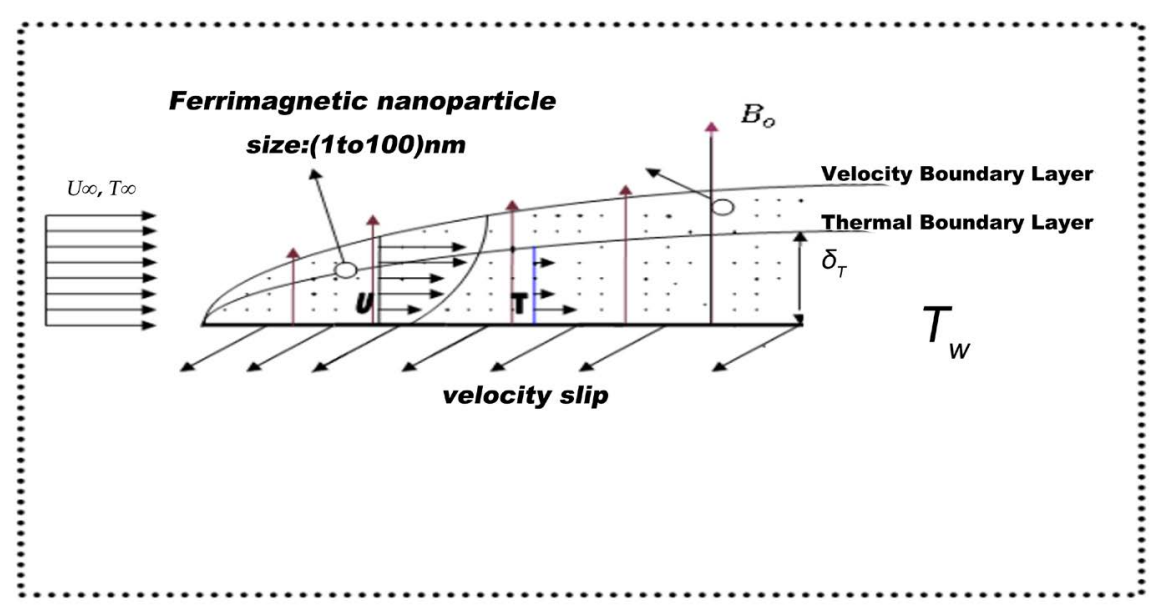

Figure 1. Schematic of the boundary layer ferrofluids along a flat plate. 
the origin and is defined as $B(x)=B_{o} x^{-\frac{1}{2}}, B_{o} \neq 0$, where $x$ is the coordinate along the plate and $B_{o}$ is the magnetic field strength [20].

Using the Rosseland approximation [25] as in Cortell [26], the radiative heat flux is simplified as:

$$
q_{r}=-\frac{4 \sigma^{*}}{3 k^{*}} \frac{\partial T^{4}}{\partial y}
$$

We assume that the temperature differences within the flow region are sufficiently small, so that the term $T^{4}$ can be expressed as a linear function of temperature. The best linear approximation of $T^{4}$ is obtained by expanding it in a Taylor series about $T_{\infty}$ and neglecting higher order terms, i.e. $T^{4} \cong 4 T_{\infty}^{3} T-3 T_{\infty}^{4}$.

So, the energy Equation (3) becomes

$$
u \frac{\partial T}{\partial x}+v \frac{\partial T}{\partial y}=\alpha_{n f} \frac{\partial^{2} T}{\partial y^{2}}+\left(\frac{1}{\rho C_{p}}\right)_{n f} \frac{16 \sigma^{*}}{3 k^{*}} T_{\infty}^{3} \frac{\partial^{2} T}{\partial y^{2}}
$$

The effective properties of ferrofluids may be expressed in terms of the properties of base fluid, ferroparticles and the volume fraction of solid nanoparticles as follows [20]:

$$
\left\{\begin{array}{l}
v_{n f}=\frac{\mu_{n f}}{\rho_{n f}}, \mu_{n f}=\frac{\mu_{f}}{(1-\varphi)^{2.5}}, \alpha_{n f}=\frac{k_{n f}}{\rho_{n f}\left(C_{p}\right)_{n f}}, \rho_{n f}=(1-\varphi) \rho_{f}+\varphi \rho_{s}, \\
\left(\rho C_{p}\right)_{n f}=(1-\varphi)\left(\rho C_{p}\right)_{f}+\varphi\left(\rho C_{p}\right)_{s}, \frac{k_{n f}}{k_{f}}=\frac{k_{s}+2 k_{f}-2 \varphi\left(k_{f}-k_{s}\right)}{k_{s}+2 k_{f}+\varphi\left(k_{f}-k_{s}\right)} .
\end{array}\right.
$$

The boundary conditions for the problem are given by

$$
\begin{gathered}
u=\gamma \frac{\partial u}{\partial y}, v=0,-k_{f} \frac{\partial T}{\partial y}=h_{f}\left(T_{w}-T\right) \text { at } y=0, \\
u \rightarrow U_{\infty}, v \rightarrow 0, T \rightarrow T_{\infty} \quad \text { as } y \rightarrow \infty,
\end{gathered}
$$

where $\gamma$ is the slip parameter. The bottom of the surface is heated due to the convective heat transfer from a hot fluid at a temperature $T_{w}$, yielding a heat transfer coefficient $h_{f}$ as a function of $x$, with its strength given as

$$
h_{f}(x)=h_{f_{0}} x^{-\frac{1}{2}}, h_{f_{0}} \neq 0 \quad[24] \text {. }
$$

We look for a similarity solution of Equation (1), Equation (2) and Equation (5) of the following form:

$$
\psi=v_{f} \sqrt{\operatorname{Re}_{x}} f(\eta), \quad \eta=\frac{y}{x} \sqrt{R e_{x}}, \theta(\eta)=\frac{T-T_{\infty}}{T_{w}-T_{\infty}},
$$

where $\eta$ is the similarity variable, $R e_{x}=\frac{U_{\infty} x}{v_{f}}$ is the local Reynolds number based on the free stream velocity and $v_{f}$ is the kinematic viscosity of the base fluid. The stream function $\psi$ is defined as

$$
u=\frac{\partial \psi}{\partial y}, v=-\frac{\partial \psi}{\partial x}
$$


Employing the similarity variables (8), Equation (1), Equation (2) and Equation (5) reduce to a nonlinear system of ordinary differential equations:

$$
\begin{gathered}
f^{\prime \prime \prime}+(1-\varphi)^{2.5}\left[\left\{(1-\varphi)+\varphi \frac{\rho_{s}}{\rho_{f}}\right\} \frac{1}{2} f f^{\prime \prime}+M\left(1-f^{\prime}\right)\right]=0, \\
\frac{\frac{k_{n f}}{k_{f}}}{\left[(1-\varphi)+\varphi\left\{\left(\rho C_{p}\right)_{s} /\left(\rho C_{p}\right)_{f}\right\}\right]} \frac{1}{\operatorname{Pr}}\left(1+\frac{4}{3} R\right) \theta^{\prime \prime}+\frac{1}{2} f \theta^{\prime}=0 .
\end{gathered}
$$

The associated boundary conditions are

$$
\begin{gathered}
f(0)=0, \quad f^{\prime}(0)=\beta f^{\prime \prime}(0), \theta^{\prime}(0)=-a\{1-\theta(0)\}, \quad \text { at } \eta=0, \\
f^{\prime}(\eta) \rightarrow 1, \theta(\eta) \rightarrow 0 \quad \text { as } \eta \rightarrow \infty .
\end{gathered}
$$

Here, primes denote differentiation with respect to $\eta, M=\sigma B_{0}^{2} / \rho U_{\infty}$ is the magnetic parameter, $\operatorname{Pr}=\frac{\mu C_{p}}{k}$ is the Prandtl number and $R=\frac{4 \sigma^{*}}{\alpha k^{*}}\left(\frac{1}{\rho C_{p}}\right) T_{\infty}^{3}$ is the radiation parameter, $a=\frac{h_{f o}}{k_{f}} \sqrt{\frac{\gamma_{f}}{U_{\infty}}}$ is the dimensionless thermal slip parameter and $\beta$ is the dimensionless slip velocity. We have to take $\gamma=c x^{\frac{1}{2}}$, where $c$ is a constant of dimension $L^{\frac{1}{2}}$. Thus we take $\beta$ as the dimensionless slip parameter ranging from zero (total adhesion) to infinity (full slip) defined by $\beta=c \sqrt{\frac{U_{\infty}}{\gamma_{f}}}$ [27]. The physical quantities of interest are the skin friction coefficient $\left(C_{f}\right)$ and the local Nusselt number $\left(N u_{x}\right)$ which are defined as

$$
C_{f}=\frac{\tau_{w x}}{\rho_{f} U_{\infty}^{2}}, N u_{x}=\frac{x q_{w}}{k_{f}\left(T_{w}-T_{\infty}\right)} .
$$

Here, $\tau_{w x}$ is the surface shear stress along the $x$ direction and $q_{w}$ is the heat flux given by

$$
\tau_{w x}=\mu_{n f}\left(\frac{\partial u}{\partial y}\right)_{y=0}, q_{w}=-k_{n f}\left(\frac{\partial T}{\partial y}\right)_{y=0} .
$$

Reducing dimensionless form we get,

$$
C_{f} R e_{x}^{\frac{1}{2}}=\frac{f^{\prime \prime}(0)}{(1-\varphi)^{2.5}}, N u_{x} R e_{x}^{-\frac{1}{2}}=\frac{k_{n f}}{k_{f}} a\{1-\theta(0)\} .
$$

\subsection{Numerical Keller Box Method}

The coupled non-linear two-point boundary value problem (9) and (10) combined with the boundary conditions (11a) and (11b) is solved numerically using the implicit finite difference scheme, the Keller-Box method.

\subsubsection{The Finite Difference Method}

As described in Cebeci and Bradshaw [28] [29] and $\mathrm{Na}$ [30] Equation (9) to Eq- 
uation (10) subject to the boundary conditions (11a) and (11b) are first written as a system of five first-order equations.

$$
\begin{aligned}
& f^{\prime}=u \\
& u^{\prime}=v \\
& s^{\prime}=t \\
& v^{\prime}+(1-\varphi)^{2.5}\left[\left(1-\varphi+\varphi \frac{\rho_{s}}{\rho_{f}}\right) \frac{1}{2} f v+M(1-u)\right]=0 \\
& \frac{\frac{k_{n f}}{k_{f}}}{\left[1-\varphi+\varphi\left\{\left(\rho C_{p}\right)_{s} /\left(\rho C_{p}\right)_{f}\right\}\right]} \frac{1}{\operatorname{Pr}}\left(1+\frac{4}{3} R\right) t^{\prime}+\frac{1}{2} f t=0
\end{aligned}
$$

In terms of the new dependent variables, the boundary conditions become

$$
\begin{gathered}
f(x, 0)=0, u(x, 0)=\beta v(x, 0), t(x, 0)=-a\{1-s(x, 0)\} \\
u(x, \infty)=1, s(x, \infty)=0
\end{gathered}
$$

We approximate the quantities $(f, u, v, s, t)$ at points $\left(x^{n}, \eta_{j}\right)$ of the net by $\left(f_{j}^{n}, u_{j}^{n}, v_{j}^{n}, s_{j}^{n}, t_{j}^{n}\right)$ which we shall call net functions. Then the system of Equation (12) is written in the finite difference form as (Figure 2)

$$
\begin{gathered}
f_{j}-f_{j-1}-\frac{h_{j}}{2}\left(u_{j}+u_{j-1}\right)=0, \\
u_{j}-u_{j-1}-\frac{h_{j}}{2}\left(v_{j}+v_{j-1}\right)=0, \\
s_{j}-s_{j-1}-\frac{h_{j}}{2}\left(t_{j}+t_{j-1}\right)=0, \\
v_{j}-v_{j-1}+h_{j}(1-\varphi)^{2.5}\left[\left(1-\varphi+\varphi \frac{\rho_{s}}{\rho_{f}}\right) \frac{1}{8}\left(f_{j}+f_{j-1}\right)\left(v_{j}+v_{j-1}\right)\right. \\
\left.+M\left\{1-\frac{1}{2}\left(u_{j}+u_{j-1}\right)\right\}\right]=\left(R_{1}\right)_{j-\frac{1}{2}}^{n-1},
\end{gathered}
$$

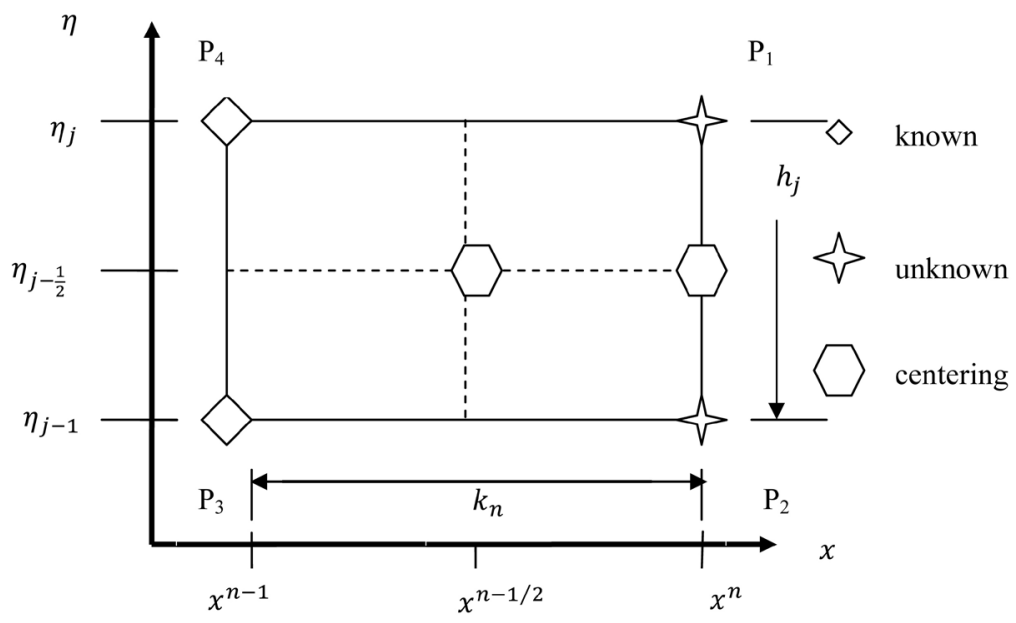

Figure 2. Net rectangle for difference approximation. 


$$
\begin{aligned}
& \frac{\frac{k_{n f}}{k_{f}}}{\left[1-\varphi+\varphi\left\{\left(\rho C_{p}\right)_{s} /\left(\rho C_{p}\right)_{f}\right\}\right]} \frac{1}{\operatorname{Pr}}\left(1+\frac{4}{3} R\right)\left(t_{j}-t_{j-1}\right) \\
& +\frac{h_{j}}{8}\left[\left(f_{j}+f_{j-1}\right)\left(t_{j}+t_{j-1}\right)\right]=\left(R_{2}\right)_{j-\frac{1}{2}}^{n-1} \text {. }
\end{aligned}
$$

Equation (14) are imposed for $j=1,2, \cdots, J$ and the transformed boundary layer thickness, $\eta_{j}$, is sufficiently large so that it is beyond the edge of the boundary layer [31]. At $x=x^{n}$ the boundary conditions (13a) and (13b) become

$$
f_{0}^{n}=0, u_{0}^{n}=\beta v_{0}^{n}, t_{0}^{n}=-a\left(1-s_{0}^{n}\right), u_{J}^{n}=1, s_{J}^{n}=0 .
$$

\subsubsection{Newton's Method}

The nonlinear system of Equation (14) is linearized using Newton's method and the following iterates are introduced

$f_{j}^{i+1}=f_{j}^{i}+\delta f_{j}^{i}, u_{j}^{i+1}=u_{j}^{i}+\delta u_{j}^{i}, v_{j}^{i+1}=v_{j}^{i}+\delta v_{j}^{i}, \quad s_{j}^{i+1}=s_{j}^{i}+\delta s_{j}^{i}, t_{j}^{i+1}=t_{j}^{i}+\delta t_{j}^{i}$

Then we obtain the following tridiagonal system,

$$
\begin{gathered}
\delta f_{j}-\delta f_{j-1}-\frac{h_{j}}{2}\left(\delta u_{j}+\delta u_{j-1}\right)=\left(r_{1}\right)_{j-\frac{1}{2}} \\
\delta u_{j}-\delta u_{j-1}-\frac{h_{j}}{2}\left(\delta v_{j}+\delta v_{j-1}\right)=\left(r_{2}\right)_{j-\frac{1 ?}{2}} \\
\delta s_{j}-\delta s_{j-1}-\frac{h_{j}}{2}\left(\delta t_{j}+\delta t_{j-1}\right)=\left(r_{3}\right)_{j-\frac{1}{2}} \\
\left(a_{1}\right)_{j} \delta v_{j}-\left(a_{2}\right)_{j} \delta v_{j-1}+\left(a_{3}\right)_{j} \delta f_{j}+\left(a_{4}\right)_{j} \delta f_{j-1} \\
-\left(a_{5}\right)_{j} \delta u_{j}-\left(a_{6}\right)_{j} \delta u_{j-1}=\left(r_{4}\right)_{j-\frac{1}{2}} \\
\left(b_{1}\right)_{j} \delta t_{j}-\left(b_{2}\right)_{j} \delta t_{j-1}+\left(b_{3}\right)_{j} \delta f_{j}+\left(b_{4}\right)_{j} \delta f_{j-1}=\left(r_{5}\right)_{j-\frac{1}{2}}
\end{gathered}
$$

where,

$$
\begin{gathered}
\left(a_{1}\right)_{j}=1+\frac{1}{4} h_{j}(1-\varphi)^{2.5}\left(1-\varphi+\varphi \frac{\rho_{s}}{\rho_{f}}\right) f_{j-\frac{1}{2}},\left(a_{2}\right)_{j}=2-\left(a_{1}\right)_{j}, \\
\left(a_{3}\right)_{j}=\frac{1}{4} h_{j}(1-\varphi)^{2.5}\left(1-\varphi+\varphi \frac{\rho_{s}}{\rho_{f}}\right) v_{j-\frac{1}{2}},\left(a_{4}\right)_{j}=\left(a_{3}\right)_{j}, \\
\left(a_{5}\right)_{j}=\frac{1}{2} M h_{j}(1-\varphi)^{2.5},\left(a_{6}\right)_{j}=\left(a_{5}\right)_{j} \\
\left(b_{1}\right)_{j}=\frac{\frac{k_{n f}}{k_{f}}}{\left[1-\varphi+\varphi\left\{\left(\rho C_{p}\right)_{s} /\left(\rho C_{p}\right)_{f}\right\}\right]} \frac{1}{\operatorname{Pr}}\left(1+\frac{4}{3} R\right)+\frac{h_{j}}{4} f_{j-\frac{1}{2}}, \\
\left(b_{2}\right)_{j}=\frac{1}{\left[1-\varphi+\varphi\left\{\left(\rho C_{p}\right)_{s} /\left(\rho C_{p}\right)_{f}\right\}\right]} \frac{1}{\operatorname{Pr}}\left(1+\frac{4}{3} R\right)-\left(b_{1}\right)_{j},
\end{gathered}
$$




$$
\left(b_{3}\right)_{j}=\frac{1}{4} h_{j} t_{j-\frac{1}{2}},\left(b_{4}\right)_{j}=\left(b_{3}\right)_{j}
$$

and

$$
\begin{gathered}
\left(r_{1}\right)_{j-\frac{1}{2}}=f_{j-1}-f_{j}+h_{j} u_{j-\frac{1}{2}}, \\
\left(r_{2}\right)_{j-\frac{1}{2}}=u_{j-1}-u_{j}+h_{j} v_{j-\frac{1}{2}}, \\
\left(r_{3}\right)_{j-\frac{1}{2}}=s_{j-1}-s_{j}+h_{j} t{ }_{j-\frac{1}{2}}, \\
\left(r_{4}\right)_{j-\frac{1}{2}}=\left(R_{1}\right)_{j-\frac{1}{2}}^{n-1}-\left(v_{j}-v_{j-1}\right)-\frac{1}{2} h_{j}(1-\varphi)^{2.5}\left(1-\varphi+\varphi \frac{\rho_{s}}{\rho_{f}}\right) f_{j-\frac{1}{2} v_{j-\frac{1}{2}}} \\
-M h_{j}(1-\varphi)^{2.5}+M h_{j}(1-\varphi)^{2.5} u_{j-\frac{1}{2}}, \\
\left(r_{5}\right)_{j-\frac{1}{2}}=\left(R_{2}\right)_{j-\frac{1}{2}}^{n-1}-\frac{k_{n f}}{k_{f}} \\
\left.-\frac{1}{2} h_{j} f_{j-\frac{1}{2} t_{j-\frac{1}{2}},}\left\{\frac{\left(\rho C_{p}\right)_{s}}{\left(\rho C_{p}\right)_{f}}\right\}\right]
\end{gathered}
$$

with

$$
\begin{aligned}
& \left(R_{1}\right)_{j-\frac{1}{2}}^{n-1}=-h_{j}\left[\frac{v_{j}-v_{j-1}}{h_{j}}+(1-\varphi)^{2.5}\left[\left(1-\varphi+\varphi \frac{\rho_{s}}{\rho_{f}}\right) \frac{1}{2}(f v)_{j-\frac{1}{2}}+M\left(1-u_{j-\frac{1}{2}}\right)\right]\right]^{n-1}, \\
& \left(R_{2}\right)_{j-\frac{1}{2}}^{n-1}=-h_{j}\left[\frac{\frac{k_{n f}}{k_{f}}}{\left[1-\varphi+\varphi\left\{\left(\rho C_{p}\right)_{s} /\left(\rho C_{p}\right)_{f}\right\}\right]} \frac{1}{\operatorname{Pr}}\left(1+\frac{4}{3} R\right) \frac{t_{j}-t_{j-1}}{h_{j}}+\frac{1}{2}(f t)_{j-\frac{1}{2}}\right]^{n-1} .
\end{aligned}
$$

To complete the system (17) we recall the boundary conditions (15) which can be satisfied exactly with no iteration [28] [29]. So, to maintain these correct values in all the iterates, we take

$$
\delta f_{0}=0, \delta u_{0}=0, \delta t_{0}=0, \delta u_{J}=0, \delta s_{J}=0 .
$$

\subsubsection{Block-Elimination Method}

The linear system (17) can now be solved numerically by the block-elimination method [30]. The linearized difference equations of the system (17) have a block-tridiagonal structure. In a matrix-vector form, this can be written as

$$
\boldsymbol{A} \boldsymbol{\delta}=\boldsymbol{r}
$$

The coefficient matrix $\boldsymbol{A}$ in (20) is known as a tridiagonal matrix due to the facts that all elements of $\boldsymbol{A}$ are zero except those on the three main diagonals. To apply the block elimination method, we assume that $\boldsymbol{A}$ is nonsingular and we seek a factorization of the form 


$$
[A]=[\boldsymbol{L}][\boldsymbol{U}]
$$

The solution of equation (21) by the block-elimination method consists of two sweeps: forward sweep, backward sweep. Once the elements of $\delta$ are found, Equation (17) can be used to find the $(i+1)$ th iteration in Equation (16). Calculations are stopped when $\left|\delta v_{0}^{(i)}\right|<\varepsilon_{1}$, where $\varepsilon_{1}$ is a small prescribed value.

\section{Results and Discussions}

The proposed numerical method is programmed in MATLAB with a step size $\eta=0.005$ and used to solve the coupled system in the interval $0 \leq \eta \leq \eta_{\max }$, where $\eta_{\max }$ is the finite value of the similarity variable $\eta$ for the far-field boundary conditions. The effects of volume fraction of solid ferroparticles, magnetic field, radiation, velocity slip parameters and Biot number on the dimensionless velocity, temperature, skin friction and Nusselt numbers are investigated for the selected ferroparticles, magnetite $\left(\mathrm{Fe}_{3} \mathrm{O}_{4}\right)$ and cobalt ferrite $\left(\mathrm{CoFe}_{2} \mathrm{O}_{4}\right)$ with two different base fluids water and kerosene. The values of Prandtl number and viscosity for the base fluids water and kerosene are taken to be 6.2, 21.0 and $8.9 \times 10^{-4}, 0.00164$ respectively. The effect of volume fraction of solid ferroparticles $\varphi$ is studied in the range $0 \leq \varphi \leq 0.2$, where $\varphi=0$ represents the pure fluid water or kerosene.

The thermophysical properties of the base fluids (water and kerosene) and the ferroparticles magnetite $\left(\mathrm{Fe}_{3} \mathrm{O}_{4}\right)$ and cobalt ferrite $\left(\mathrm{CoFe}_{2} \mathrm{O}_{4}\right)$ are listed in Table 1.

In order to validate the accuracy of our numerical procedure, the skin friction coefficient is computed for pure fluid, magnetite and cobalt ferrite for specific values of velocity slip, magnetic parameters (Table 2) and the heat transfer rate

Table 1. Thermophysical properties of base fluids and nanoparticle [20].

\begin{tabular}{cccc}
\hline Materials & $\rho\left(\mathrm{kg} / \mathrm{m}^{3}\right)$ & $C_{p}(\mathrm{~J} /(\mathrm{kg} \cdot \mathrm{K}))$ & $k(\mathrm{~W} /(\mathrm{m} \cdot \mathrm{K}))$ \\
\hline Water & 997 & 4179 & 0.613 \\
Kerosene & 783 & 2090 & 0.15 \\
$\mathrm{Fe}_{3} \mathrm{O}_{4}$ & 5180 & 670 & 9.7 \\
$\mathrm{CoFe}_{2} \mathrm{O}_{4}$ & 4907 & 700 & 3.7 \\
\hline
\end{tabular}

Table 2. Comparison of skin friction coefficient $C_{f}$ for specific values of velocity slip, volume fraction of solid nanoparticles and magnetic parameters.

\begin{tabular}{ccccccccc}
\hline Materials & $\varphi$ & $\beta$ & $M$ & Blasius [32] & Cortell [33] & Yazdi [24] & Khan [20] & Present Work \\
\hline Pure & 0.0 & 0.0 & 0.0 & 0.3321 & 0.33206 & - & 0.33206 & 0.33206 \\
Fluid & 0.0 & 0.0 & 1.0 & - & - & 1.0440 & 1.04400 & 1.0440 \\
& 0.0 & 0.5 & 1.0 & - & - & 0.6987 & 0.69872 & 0.6989 \\
$\mathrm{Fe}_{3} \mathrm{O}_{4}$ & 0.01 & 0.0 & 0.0 & - & - & - & 0.34324 & 0.34324 \\
& 0.1 & 0.0 & 0.0 & - & - & - & 0.45131 & 0.45132 \\
$\mathrm{CoFe}_{2} \mathrm{O}_{4}$ & 0.01 & 0.0 & 0.0 & - & - & - & 0.34278 & 0.34279 \\
& 0.1 & 0.0 & 0.0 & - & - & - & 0.44694 & 0.44692 \\
\hline
\end{tabular}


or Nusselt number is computed for pure fluids for specific values of Prandtl number, Biot number, magnetic parameter and velocity slip parameters (Table 3). It is well established that our results are well matched with the previous studies.

From Table 4, we see that for both water-based and kerosene-based ferrofluids, skin friction coefficient and Nusselt number increase with the increase of magnetic parameter and volume fraction. For pure fluids, skin friction coefficient is minimum for each case. When there is no slip, there is high resistance to fluid flow. As the velocity slip parameter increases, the flow resistance decreases and as a result skin friction coefficient also decreases with the increase of velocity slip parameter. In case of no slip, the Nusselt number is found to be minimum and they increase with increasing velocity slip parameter. The skin friction coefficient remains same for increasing radiation parameter and Biot number. The heat transfer coefficient or the Nusselt number increases with the increase of Biot number but decreases with the increase of radiation parameter. For every cases, kerosene-based ferrofluid has higher skin friction coefficient and Nusselt number than water-based ferrofluid. This is due to lower density and higher Prandtl number of kerosene-based ferrofluid. Again, for both water-based and kerosene-based, magnetite $\left(\mathrm{Fe}_{3} \mathrm{O}_{4}\right)$ has higher skin friction and heat transfer rate or Nusselt number than cobalt ferrite $\left(\mathrm{CoFe}_{2} \mathrm{O}_{4}\right)$. The same behavior was observed by Khan et al. [20] using the Runge-Kutta-Fehlberg method.

The effects of parameters variation on the dimensionless velocity and temperature profiles of water-based and kerosene-based magnetite $\left(\mathrm{Fe}_{3} \mathrm{O}_{4}\right)$ and cobalt ferrite $\left(\mathrm{CoFe}_{2} \mathrm{O}_{4}\right)$ are plotted in Figures 3-7.

The variation of the dimensionless velocity and temperature profiles with magnetic parameter $M$ is shown in Figure 3 for magnetite and cobalt ferrite in base fluids, water and kerosene. In each case, the dimensionless velocity profile (Figure 3(a) and Figure 3(c)) increases at the surface and within the boundary layer with the increase of magnetic parameter. In the absence of magnetic field, the dimensionless velocity is found to be smaller. As the magnetic field is applied, it arranges the ferroparticle in order and enhances the velocity. The effect of magnetic parameter on dimensionless temperature is shown in Figure 3(b) (magnetite) and Figure 3(d) (cobalt ferrite) respectively. It is evident that the

Table 3. Comparison of heat transfer coefficient $N u_{x}$ in the absence of ferromagnetic particles i.e. $\varphi=0$.

\begin{tabular}{cccccccc}
\hline$P r$ & $M$ & $\beta$ & $a$ & Aziz [22] & Ishak [23] & Yazdi [24] & Present Work \\
\hline & 1.0 & 0.0 & 0.01 & - & - & 0.0098 & 0.0098 \\
1.0 & 1.0 & 0.5 & 0.5 & - & - & 0.2417 & 0.2417 \\
& 1.0 & 0.5 & 1.0 & - & - & 0.3188 & 0.3182 \\
& 0.0 & 0.0 & 0.1 & 0.0747 & 0.0747 & 0.0757 & 0.0748 \\
0.72 & 0.0 & 0.0 & 1.0 & 0.2282 & 0.2282 & 0.2282 & 0.2287 \\
\hline
\end{tabular}


Table 4. Effects of parameters variation on the skin friction coefficient and heat transfer coefficient.

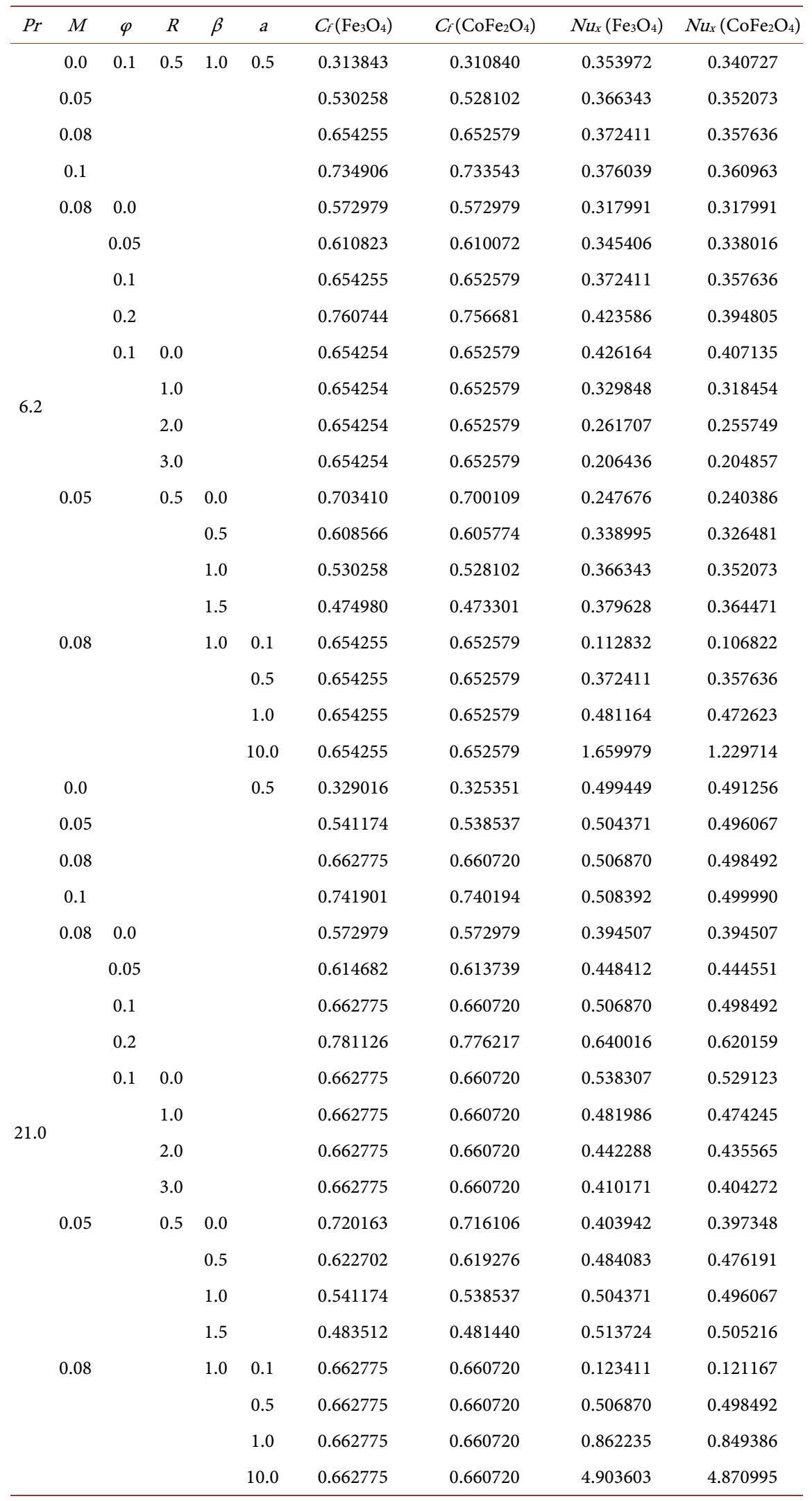




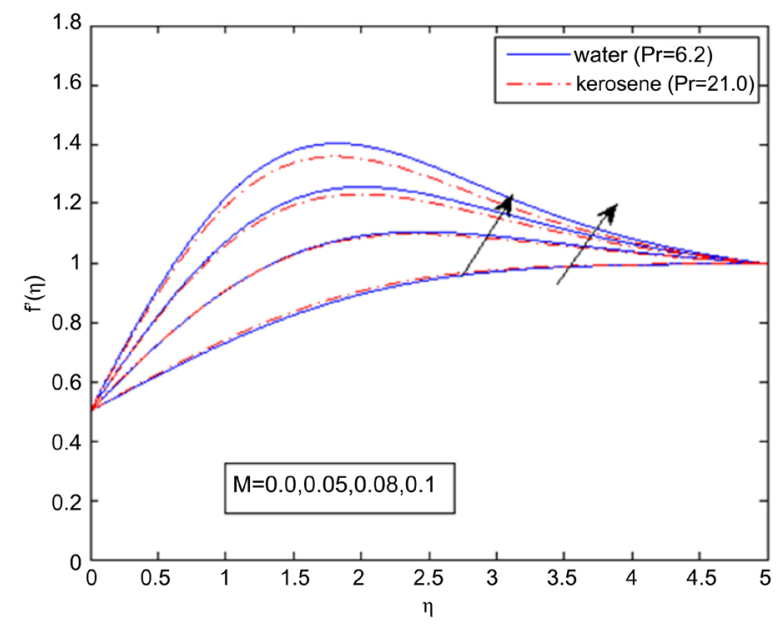

(a)

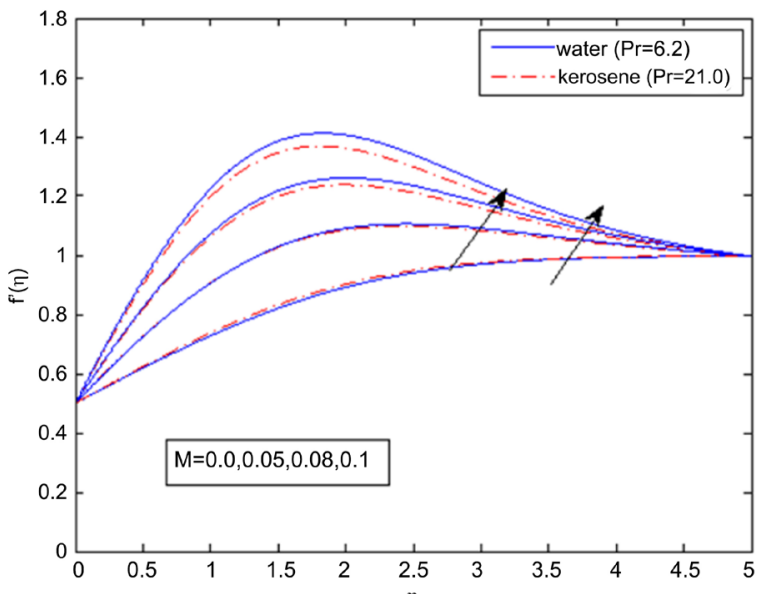

(c)

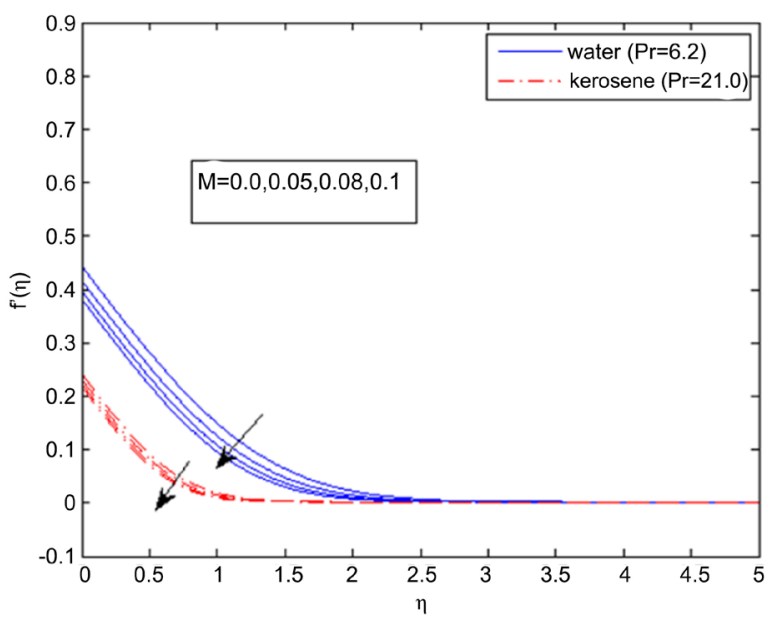

(b)

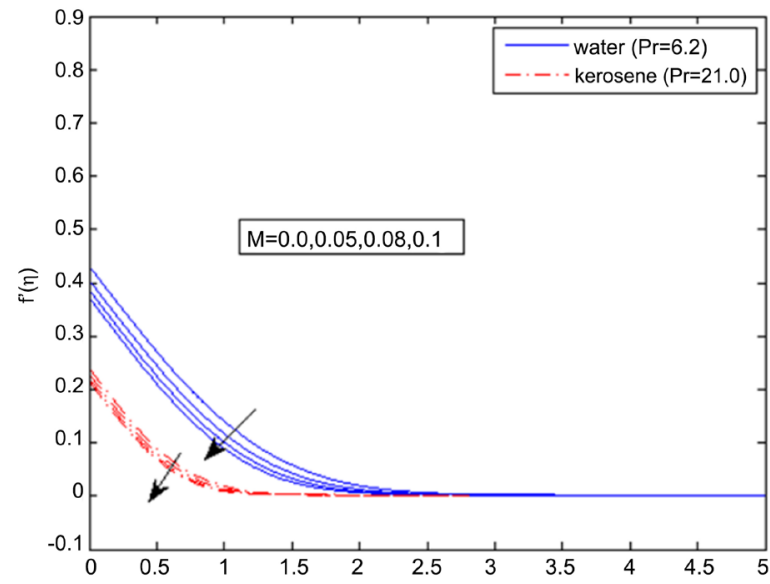

(d)

Figure 3. (a) Variation of velocity profiles of magnetite with magnetic parameter $(M)(\varphi=0.1, R=0.5, \beta=1.0, a=0.5)$; (b) Variation of temperature profiles of magnetite with magnetic parameter $(M) \quad(\varphi=0.1, R=0.5, \beta=1.0, a=0.5)$; (c) Variation of velocity profiles of cobalt ferrite with magnetic parameter $(M)(\varphi=0.1, R=0.5, \beta=1.0, a=0.5)$; (d) Variation of temperature profiles of cobalt ferrite with magnetic parameter $(M)(\varphi=0.1, R=0.5, \beta=1.0, a=0.5)$.

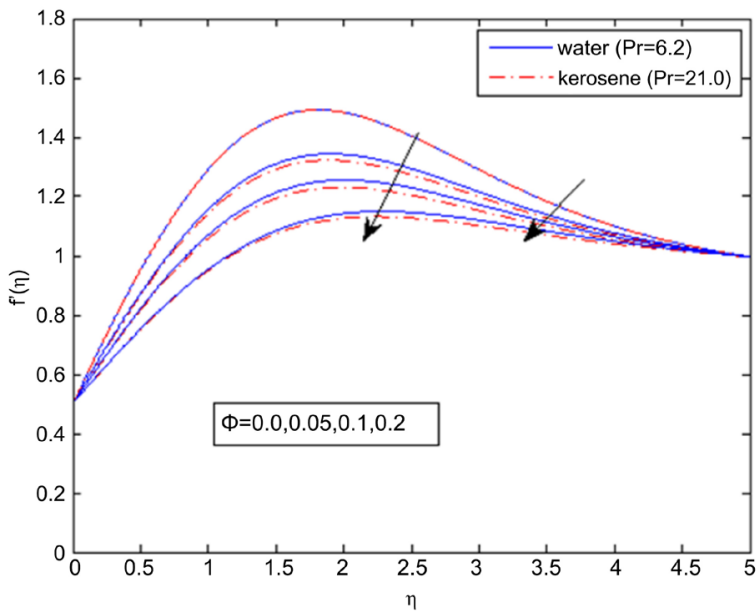

(a)

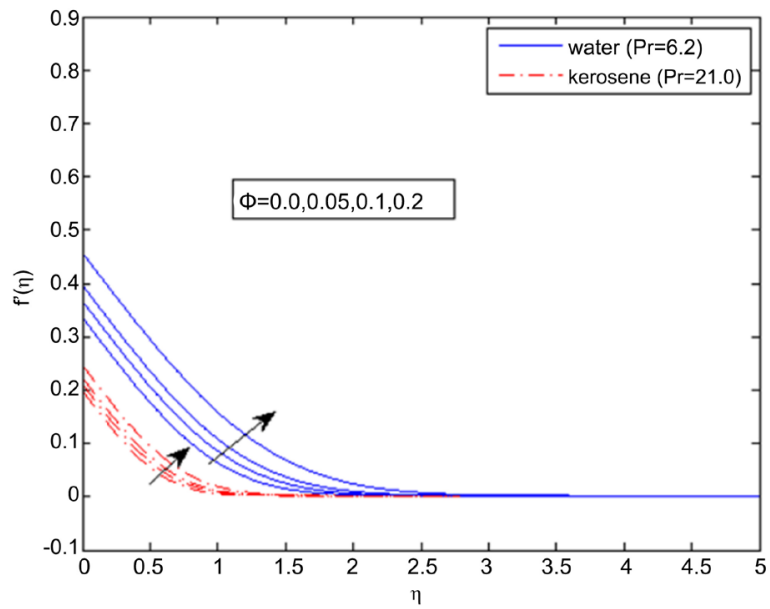

(b) 


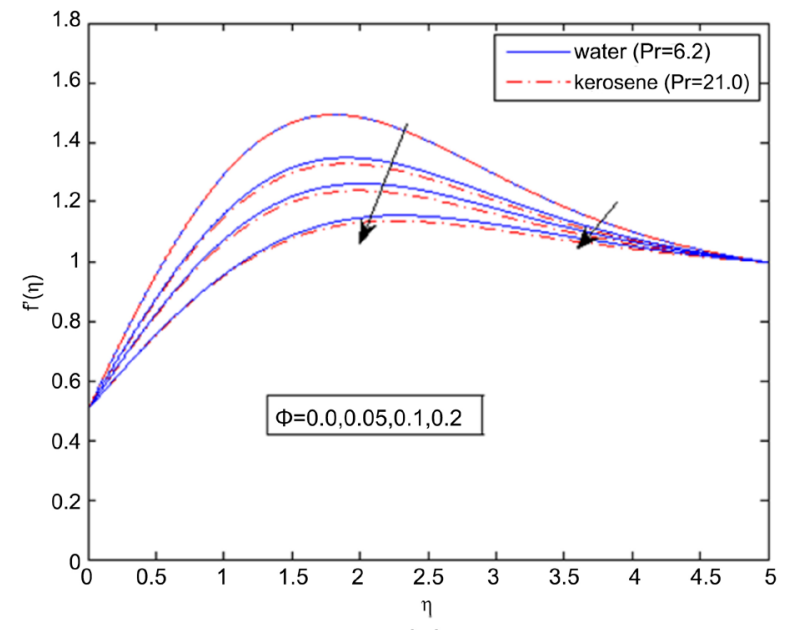

(c)

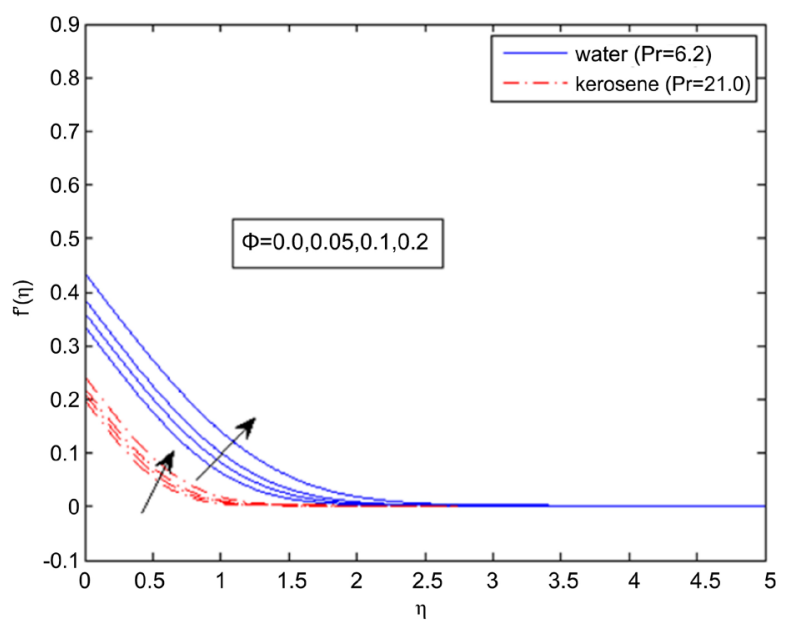

(d)

Figure 4. (a) Variation of velocity profiles of magnetite with volume fraction $(\varphi) \quad(M=0.08, R=0.5, \beta=1.0, a=0.5)$; (b) Variation of temperature profiles of magnetite with volume fraction $(\varphi) \quad(M=0.08, R=0.5, \beta=1.0, a=0.5)$; (c) Variation of velocity profiles of cobalt ferrite with volume fraction $(\varphi) \quad(M=0.08, R=0.5, \beta=1.0, a=0.5)$; (d) Variation of temperature profiles of cobalt ferrite with volume fraction $(\varphi) \quad(M=0.08, R=0.5, \beta=1.0, a=0.5)$.

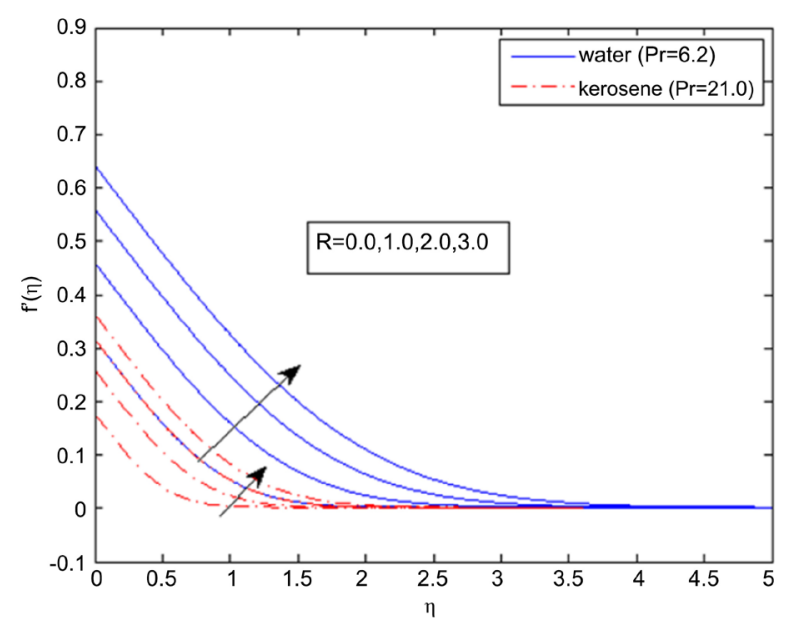

(a)

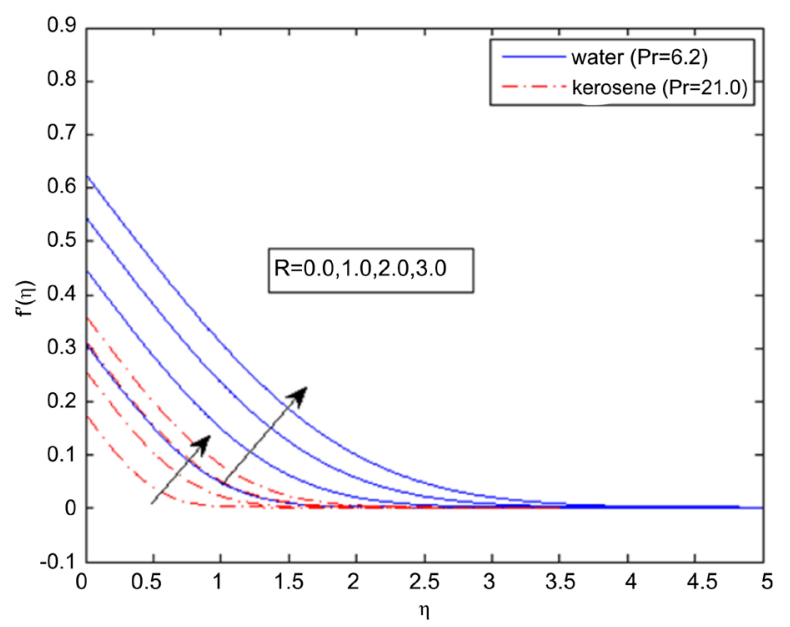

(b)

Figure 5. (a) Variation of temperature profiles of magnetite with radiation parameter $(R) \quad(M=0.08, \varphi=0.1, \beta=1.0, a=0.5)$; (b) Variation of temperature profiles of cobalt ferrite with radiation parameter $(R) \quad(M=0.08, \varphi=0.1, \beta=1.0, a=0.5)$.

increase of the magnetic parameter $M$ results in the decrease of temperature profiles. Figure 4(a), Figure 4(c) show the effect of volume fraction $\varphi$ of ferrofluids on velocity profile. In both cases, the dimensionless velocity profile decreases with increasing volume fraction $\varphi$. In the absence of volume fraction, the velocity is found to be highest. From Figure 4(b) and Figure 4(d) we observe that, increase in the volume fraction increases the dimensionless temperature for both ferrofluids. In fact, addition of $\varphi$ increases the thermal conductivity of the pure fluid and thus results in increasing the thermal diffusion in the boundary layer. Figure 5(a), Figure 5(b) indicates that the increase in radiation parameter 


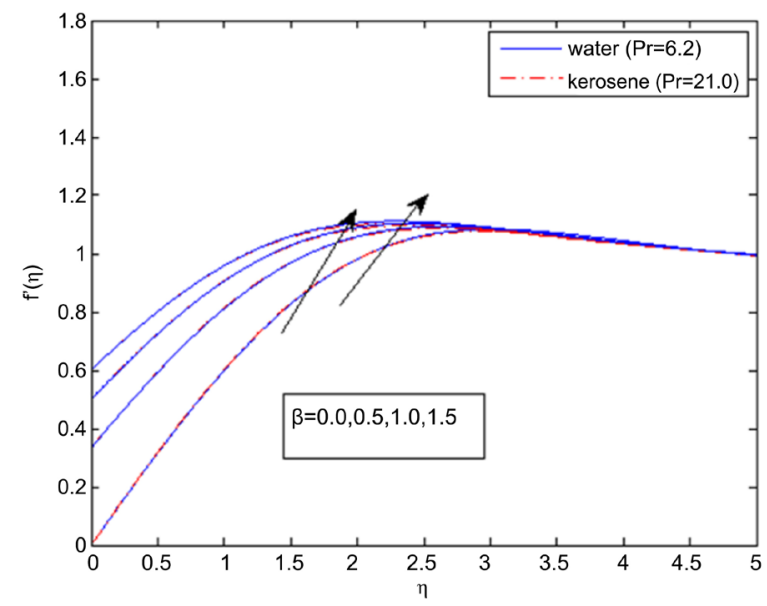

(a)

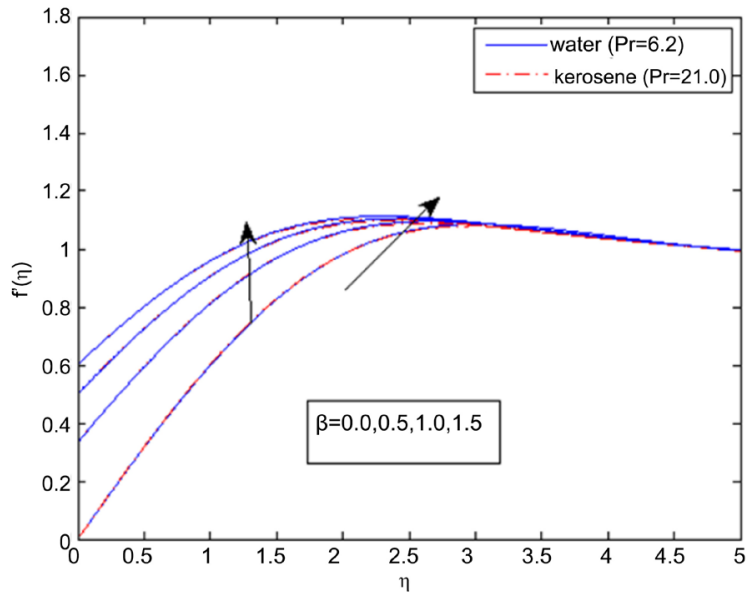

(c)

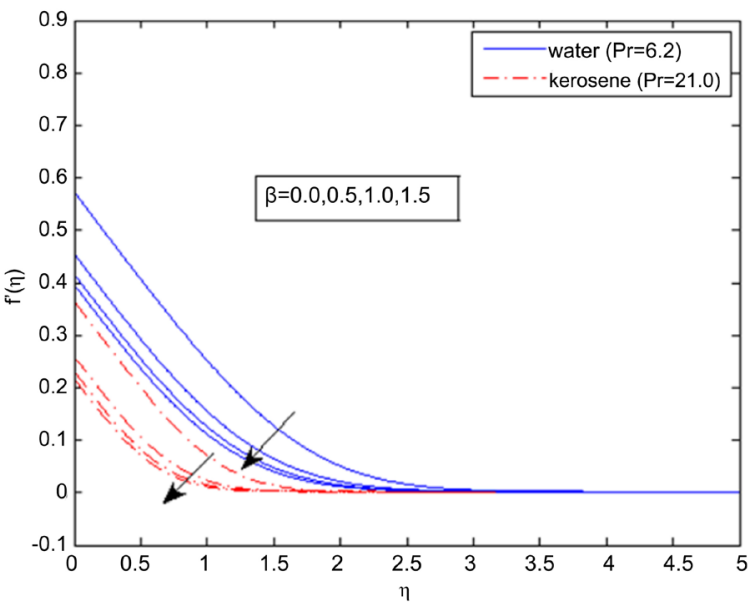

(b)

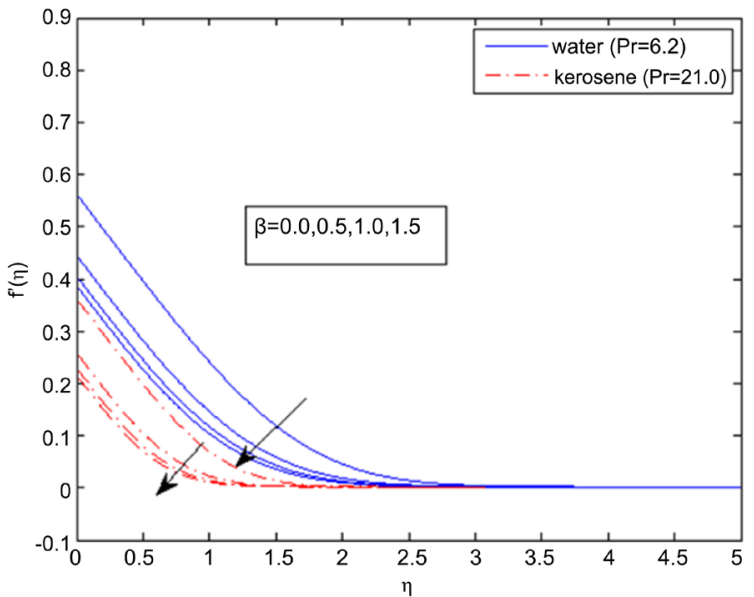

(d)

Figure 6. (a) Variation of velocity profiles of magnetite with velocity slip parameter $(\beta) \quad(M=0.05, \varphi=0.1, R=0.5, a=0.5) ;(\mathrm{b})$ Variation of temperature profiles of magnetite with velocity slip parameter $(\beta) \quad(M=0.05, \varphi=0.1, R=0.5, a=0.5)$; (c) Variation of velocity profiles of cobalt ferrite with velocity slip parameter $(\beta) \quad(M=0.05, \varphi=0.1, R=0.5, a=0.5)$; (d) Variation of temperature profiles of cobalt ferrite with velocity slip parameter $(\beta) \quad(M=0.05, \varphi=0.1, R=0.5, a=0.5)$.

$R$ increases $\theta(\eta)$ and hence the thermal boundary layer thickness. s variation of the dimensionless velocity profiles for magnetite and cobalt ferrite respectively, for various values of velocity slip parameter $\beta$. When there is no slip, i.e. $\beta=0$, the velocity is at the boundary of the wall. It is noted that the increase in velocity slip $\beta$ corresponds to a rise in the fluid velocity adjacent to the wall. Temperature profiles for numerous values of velocity slip parameter $\beta$ are shown in Figure 6(b) (magnetite) and Figure 6(d) (cobalt ferrite). It is noted that, at high velocity slip parameter, the temperature reduces faster and the boundary layer becomes thinner. An increase in the thermal slip parameter, i.e. Biot numbera leads to an increase in the temperature profile as shown in Figure 7(a) and Figure 7(b). A high Biot number $a$ indicates that the internal thermal resistance of the plate is higher than the boundary layer thermal resistance and hence an enhancement of thermal boundary layer. However, the Biot 


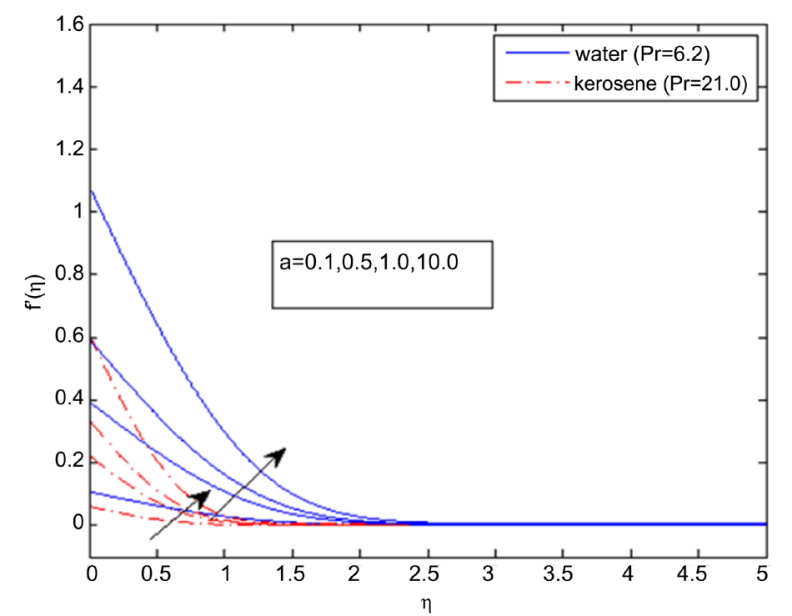

(a)

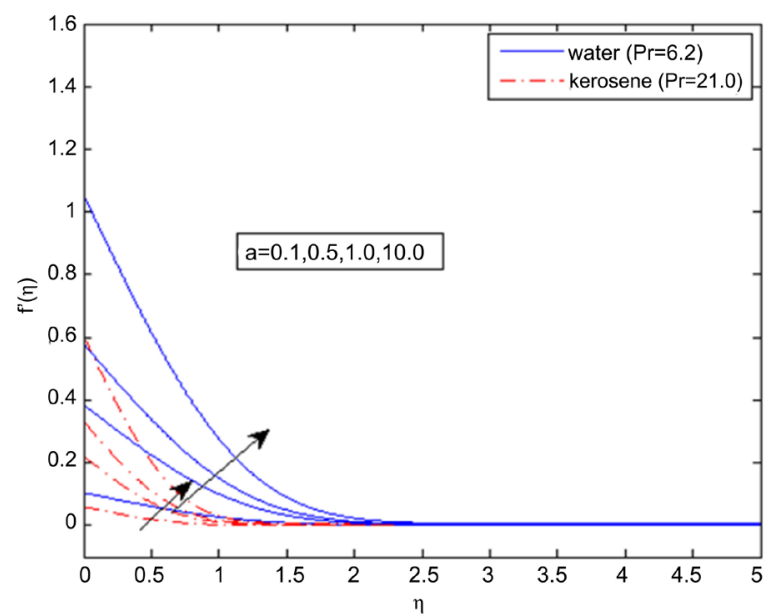

(b)

Figure 7. (a) Variation of temperature profiles of magnetite with Biot number (a) $(M=0.08, \varphi=0.1, R=0.5, \beta=1.0)$; (b) Variation of temperature profiles of cobalt ferrite with Biot number (a) $(M=0.08, \varphi=0.1, R=0.5, \beta=1.0)$.

number has no effect on the velocity profiles as radiation parameter regardless of the base fluid or ferroparticles. For each case, it is observed that due to the higher Prandtl number of kerosene, the thermal boundary layer thickness as well as the dimensionless surface temperature is smaller for kerosene-based ferrofluids.

\section{Conclusions}

The present study investigates the flow and heat transfer of ferrofluids over a flat plate with slip conditions and radiation using the Keller-Box method. For each ferrofluid, it is concluded that:

- The skin friction coefficient increases with the increase of magnetic field, volume fraction of solid ferroparticles and decreases with increasing velocity slip parameter, but remains the same for variation of radiation parameter and Biot number.

- The heat transfer rate or Nusselt number increases with increasing magnetic parameter, volume fraction, velocity slip parameter, Biot number and decreases with increasing radiation parameter.

- Kerosene-based ferrofluids have higher skin friction and heat transfer rate than the water-based ferrofluids.

- Kerosene-based magnetite $\left(\mathrm{Fe}_{3} \mathrm{O}_{4}\right)$ provides the higher skin friction coefficient and heat transfer rate at the wall compared to the kerosene-based cobalt ferrite $\left(\mathrm{CoFe}_{2} \mathrm{O}_{4}\right)$.

- In the slip flow regime, under low Biot number conditions, the permeability effects on heat transfer rate tend to be negligible.

- The dimensionless velocity profiles increase with the increase of magnetic parameter and velocity slip parameter, decrease with the increase of volume fraction of solid nanoparticles and there is no effect with the variation of radiation parameter and Biot number. 
- The dimensionless temperature profile increases with the increase of volume fraction of solid nanoparticles, radiation parameter, Biot number and decreases with the increase of magnetic and velocity slip parameter.

For future work, investigation can be carried out to study the effects of magnetic field, radiation, slip conditions, viscous dissipation, internal heating, suction, injection of ferrofluids for unsteady case and turbulent flow.

\section{Conflicts of Interest}

The authors declare no conflicts of interest regarding the publication of this paper.

\section{References}

[1] Nkurikiyimfura, I., Wang, Y.M. and Pan, Z.D. (2013) Heat Transfer Enhancement by Magnetic Nanofluids-A Review. Renewable and Sustainable Energy Reviews, 21, 548-561. https://doi.org/10.1016/j.rser.2012.12.039

[2] Vadasz, J.J., Govender, S. and Peter, V. (2005) Heat Transfer Enhancement in Nanofluid Suspensions: Possible Mechanisms and Explanations. International Journal of Heat and Mass Transfer, 48, 2673-2683.

https://doi.org/10.1016/j.ijheatmasstransfer.2005.01.023

[3] Berkovsky, B.M., Medvedev, V.F. and Krakov, M.S. (1993) Magnetic Fluids: Engineering Applications. Oxford University Press, Oxford, 256.

[4] Genc, S. and Bora, D. (2014) Synthesis and Rheology of Ferrofluids: A Review. Current Opinion in Chemical Engineering, 3, 118-124. https://doi.org/10.1016/j.coche.2013.12.006

[5] López-López, M.T., Gómez-Ramírez, A., Rodríguez-Arco, L., Durán, J.D.G., Iskakova, L. and Zubarev, A. (2012) Colloids on the Frontier of Ferrofluids, Rheological Properties. Langmuir, 28, 6232-6245. https://doi.org/10.1021/la204112w

[6] Rosensweig, R.E. (1985) Ferrohydrodynamics. Cambridge University Press, Cambridge.

[7] Ajadi, S.O., Adegoke, A. and and Aziz, A. (2009) Slip Boundary Layer Flow of Non-Newtonian Fluidover a Flat Plate with Convective Thermal Boundary Condition. International Journal of Nonlinear Science, 8, 300-306.

[8] Choi, S.U.S. and Eastman, J.A. (1995) Enhancing Thermal Conductivity of Fluids with Nanoparticles. ASME International Mechanical Engineering Congress \& EXposition, San Francisco, 12-17 November 1995.

[9] Das, S.K., Choi, S.U.S. and Patel, H.E. (2006) Heat Transfer in Nanofluids-A Review. Heat Transfer Engineering, 27, 3-19.

https://doi.org/10.1080/01457630600904593

[10] Noor, N.F.M., Abdulaziz, O. and Hashim, I. (2010) MHD Flow and Heat Transfer in a Thin Liquid Film on an Unsteady Stretching Sheet by the Homotopy Analysis Method. International Journal for Numerical Methods in Fluids, 63, 357. https://doi.org/10.1002/fld.2078

[11] Noor, N.F.M., Abbasbandy, S. and Hashim, I. (2012) Heat and Mass Transfer of Thermophoretic MHD Flow over an Inclined Radiate Isothermal Permeable Surface in the Presence of Heatsource/Sink. International Journal of Heat and Mass Transfer, 55, 2122-2128. https://doi.org/10.1016/j.ijheatmasstransfer.2011.12.015 
[12] Haq, R.U., Nadeem, S., Khan, Z.H. and Noor, N.F.M. (2015) Convective Heat Transfer in MHD Slip Flow over a Stretching Surface in the Presence of Carbon Nanotubes. Physica B: Condensed Matter, 40, 457. https://doi.org/10.1016/j.physb.2014.09.031

[13] Nadeem, S., Haq, R.U., Akbar, N.S. and Khan, Z.H. (2013) MHD Three-Dimensional Casson Fluidflow Past a Porous Linearly Stretching Sheet. Alexandria Engineering Journal, 52, 577-582. https://doi.org/10.1016/j.aej.2013.08.005

[14] Haq, R.U., Nadeem, S., Khan, Z.H. and Akbar, N.S. (2015) Thermal Radiation and Slip Effects on MHD Stagnation Point Flow of Nanofluid over a Stretching Sheet. Physica E, 65, 17-23. https://doi.org/10.1016/j.physe.2014.07.013

[15] Cao, K. and Baker, J. (2009) Slip Effects on Mixed Convective Flow and Heat Transfer from Avertical Plate. International Journal of Heat and Mass Transfer, 52, 3829-3841. https://doi.org/10.1016/j.ijheatmasstransfer.2009.02.013

[16] Hayat, T., Qasim, M. and Mesloub, S. (2011) MHD Flow and Heat Transfer over Permeable Stretching Sheet with Slip Conditions. International Journal for Numerical Methods in Fluids, 66, 963-975. https://doi.org/10.1002/fld.2294

[17] Qasim, M., Hayat, T. and Hendi, A.A. (2011) Effects of Slip Conditions on Stretching Flow with Ohmic Dissipation and Thermal Radiation. Heat Transfer-Asian Research, 40, 641-654. https://doi.org/10.1002/htj.20367

[18] Fang, T., Yao, S., Zhang, J. and Aziz, A. (2010) Viscous Flow over a Shrinking Sheet with a Second Order Slip Flow Model. Communications in Nonlinear Science and Numerical Simulation, 15, 1831-1842. https://doi.org/10.1016/j.cnsns.2009.07.017

[19] Abbas, Z., Wang, Y., Hayat, T. and Oberlack, M. (2009) Slip Effects and Heat Transfer Analysis in Aviscous Fluid over an Oscillatory Stretching Surface. International Journal for Numerical Methods in Fluids, 59, 443-458. https://doi.org/10.1002/fld.1825

[20] Khan, W.A., Khan, Z.H. and Haq, R.U. (2015) Flow and Heat Transfer of Ferrofluids over a Flat Plate with Uniform Heat Flux. The European Physical Journal Plus, 130, 86. https://doi.org/10.1140/epjp/i2015-15086-4

[21] Rahman, M.M. (2011) Locally Similar Solutions for Hydromagnetic and Thermal Slip Flow Boundary Layers over a Flat Plate with Variable Fluid Properties and Convective Surface Boundary Condition. Meccanica, 46, 1127-1143. https://doi.org/10.1007/s11012-010-9372-2

[22] Aziz, A. (2009) A Similarity Solution for Laminar Thermal Boundary Layer over a Flat Plate with Convective Surface Boundary Condition. Communications in Nonlinear Science and Numerical Simulation, 14, 1064-1068. https://doi.org/10.1016/j.cnsns.2008.05.003

[23] Ishak, A. (2010) Similarity Solutions for Flow and Heat Transfer over a Permeable Surface with Convective Boundary Condition. Applied Mathematics and Computation, 217, 837-842. https://doi.org/10.1016/j.amc.2010.06.026

[24] Yazdi, M.H., Abdullah, S., Hashim, I. and Sopian, K. (2011) Effects of Viscous Dissipation on the Slip MHD Flow and Heat Transfer past a Permeable Surface with Convective Boundary Conditions. Energies, 4, 2273-2294. https://doi.org/10.3390/en4122273

[25] Rosseland, S. (1931) Astrophysik und atom-theoretische Grundlagen. Springer, Berlin. https://doi.org/10.1007/978-3-662-26679-3

[26] Cortell, R. (2008) Effect of Viscous Dissipation and Radiation on the Thermal Boundary Layer over a Non-Linearly Stretching Sheet. Physics Letters A, 372, 
631-636. https://doi.org/10.1016/j.physleta.2007.08.005

[27] Ramli, N., Ahmad, S. and Pop, L. (2017) Slip Effects on MHD Flow and Heat Transfer of Ferrofluids over a Moving Heat Plate. American Institute of Physics, College Park, 1870. https://doi.org/10.1063/1.4995847

[28] Cebeci, T. and Bradshaw, P. (1977) Momentum Transfer in Boundary Layers. Hemisphere, Washington DC.

[29] Cebeci, T. and Bradshaw, P. (1988) Physical and Computational Aspects of Convective Heat Transfer. Springer, New York. https://doi.org/10.1007/978-1-4612-3918-5

[30] Na, T.Y. (1979) Computational Methods in Engineering Boundary Value Problem. Academic Press, New York.

[31] Keller, H.B. and Cebeci, T. (1972) Accurate Numerical Methods for Boundary Layer Flows, 2: Two-Dimensional Turbulent Flows. AIAA Journal, 10, 1193-1199. https://doi.org/10.2514/3.50349

[32] Blasius, H. (1908) The Boundary Layers in Fluids with Little Friction. Zeitschrift für Angewandte Mathematik und Physik, 56, 1-37.

[33] Cortell, R. (2005) Numerical Analysis of Dynamic Problems: An Alternative Integration. Applied Mathematics and Computation, 170, 158-171.

https://doi.org/10.1016/j.amc.2004.10.090 


\section{Nomenclature}

\begin{tabular}{|c|c|c|c|}
\hline & Nomenclature & & Greek Symbols \\
\hline$B_{o}$ & Magnetic field intensity & $\sigma$ & Electric conductivity \\
\hline$C_{p}$ & Specific Heat at constant pressure $[\mathrm{J} / \mathrm{kg} \cdot \mathrm{K}]$ & $\sigma^{*}$ & Stefan-Boltzmann constant \\
\hline$C_{f}$ & Skin Friction coefficient & $k^{*}$ & Mean absorption coefficient \\
\hline$f$ & Dimensionless Stream function & $\beta$ & Velocity slip parameter \\
\hline$f^{\prime}$ & Dimensionless velocity & $\gamma$ & Dimensionless distance \\
\hline$q_{r}$ & Radiative heat flux & $\varphi$ & Volume fraction of ferrofluid \\
\hline$R$ & Radiation parameter & $\eta$ & Similarity variable \\
\hline$k$ & Thermal conductivity $[\mathrm{W} / \mathrm{m} \cdot \mathrm{K}]$ & $\theta$ & Dimensionless temperature \\
\hline $\operatorname{Pr}$ & Prandtl number & $\mu$ & Absolute viscosity $\left[\mathrm{N} \cdot \mathrm{s} / \mathrm{m}^{2}\right]$ \\
\hline$M$ & Magnetic parameter & $v$ & Kinematic viscosity $\left[\mathrm{m}^{2} / \mathrm{s}\right]$ \\
\hline$a$ & Biot number & $\rho$ & Fluid density $\left[\mathrm{kg} / \mathrm{m}^{3}\right]$ \\
\hline$R e_{x}$ & Local Reynolds number & $\rho C_{p}$ & Heat capacity $\left.\left[\mathrm{kg} / \mathrm{m}^{3} \cdot \mathrm{K}\right)\right]$ \\
\hline$q_{w}$ & Wall heat flux $\left[\mathrm{W} / \mathrm{m}^{2}\right]$ & $\psi$ & Stream Function \\
\hline$N u_{x}$ & Local Nusselt number & $\alpha$ & Thermal conductivity $\left[\mathrm{m}^{2} / \mathrm{s}\right]$ \\
\hline$U_{\infty}$ & Free stream velocity $[\mathrm{m} / \mathrm{s}]$ & & Subscripts \\
\hline$u, V$ & $\begin{array}{l}\text { Velocity components in the } x, y \\
\text { directions }[\mathrm{m} / \mathrm{s}]\end{array}$ & $n f$ & Nanofluid \\
\hline$x, y$ & Distance along and normal to the plate $[\mathrm{m}]$ & $f$ & Base fluid \\
\hline$T$ & Local fluid Temperature $[\mathrm{K}]$ & $s$ & Solid ferroparticles \\
\hline$T_{\infty}$ & Temperature of the ambient fluid $[\mathrm{K}]$ & $n, j$ & $\begin{array}{l}\text { Sequence of numbers that indicate the } \\
\qquad x, \eta\end{array}$ \\
\hline$T_{w}$ & Temperature at the surface of the plate $[\mathrm{K}]$ & & coordinate location \\
\hline$t$ & Time $[\mathrm{s}]$ & & \\
\hline$h_{f}$ & $\begin{array}{l}\text { Convective heat transfer coefficient } \\
\qquad\left[\mathrm{W} / \mathrm{m}^{2} \cdot \mathrm{K}\right]\end{array}$ & & \\
\hline
\end{tabular}

